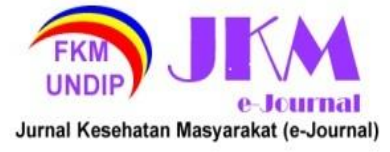

JURNAL KESEHATAN MASYARAKAT (e-Journal)

Volume 9, Nomor 6, November 2021

ISSN: 2715-5617 / e-ISSN: 2356-3346

http://ejournal3.undip.ac.id/index.php/jkm

\title{
HUBUNGAN SIKAP KERJA BERDIRI, KARAKTERISTIK PEKERJA, DAN PENGGUNAAN HIGH HEELS TERHADAP TINGKAT KELELAHAN KERJA PADA SALES PROMOTION GIRL (SPG) DI SWALAYAN KOTA SEMARANG
}

\author{
Aisya Mauliana Maharani ${ }^{1 *}$, Ida Wahyuni ${ }^{2}$, Baju Widjasena ${ }^{2}$ \\ ${ }_{1}^{1}$ Peminatan Keselamatan dan Kesehatan Kerja Fakultas Kesehatan Masyarakat, Universitas Diponegoro, \\ Jl. Prof. H. Soedarto, S.H.,Tembalang, Semarang, Indonesia \\ 2Bagian Keselamatan dan Kesehatan Kerja Fakultas Kesehatan Masyarakat, Universitas Diponegoro, \\ Jl. Prof. H. Soedarto, S.H.,Tembalang, Semarang, Indonesia \\ ${ }^{*}$ Corresponding author : aisyamaharani5@gmai.com
}

This study aims to determine whether there is a relationship among standing work attitude, worker characteristics, and the use of high heels on work fatigue experienced by Sales Promotion Girl (SPG) in Semarang City Supermarkets. The background of the research is that a SPG who works with a standing work position and wears high heels will experience an incidence of work fatigue. This is quantitative research with a cross-sectional study approach. The instruments in this study were the IFRC questionnaire, ruler, microtoise, body scale, and REBA Method Sheet. The population in this research consists of 150 people. The research employed an incidental sampling with a total sample of 38 people. Data analysis in this research made use of the Spearman rank correlation test. The findings of the research showed that among the 38 Sales Promotion Girls (SPG) who had a standing work position; 16 people were with low risk and 22 people were very low. Based on their ages, 9 people were 30 years old and 29 people were below 30 years old. As with their service time category, as many as 24 people had a long time experience and 14 people were with short period of service time. The results of the statistical test showed that there is a significant correlation between standing work position, wearing of high heels with work fatigue. In addition, there is no significant correlation between worker characteristics (Age, Work Period, Body Mass Index) and work fatigue on SPG at Supermarkets in Semarang City.

\section{Keyword : Sales Promotion Girl, Fatigue}

\section{PENDAHULUAN}

Dewasa ini banyak pekerja perempuan yang dituntut untuk berpenampilan cantik, anggun, dan menarik. Seorang Sales Promotion Girl (SPG) bertugas untuk mempromosikan suatu produk kepada para calon konsumen dan membantu konsumen untuk menemukan barang yang dibutuhkannya. Sehingga seorang Sales Promotion Girl (SPG) dituntut harus memiliki skill komunikasi yang baik, dan dari segi fisik juga harus terlihat menarik. ${ }^{1}$ Salah satu cara untuk menunjang penampilannya adalah dengan menggunakan sepatu high heels. High heels merupakan sepatu dengan model tumit yang lebih tinggi dari jari-jari kaki, dengan berbagai macam bentuk dan tinggi. ${ }^{2}$ Sales Promotion Girl (SPG) bekerja selama 7 sampai 8 jam per hari dengan 6 hari kerja dalam 1 minggu. Seorang Sales Promotion Girl (SPG) diwajibkan menggunakan sepatu high heels dengan minimal tinggi $3 \mathrm{~cm}$ dan dengan sikap kerja yang berdiri secara terus-menerus. Posisi kaki yang terus-menerus menjinjit dalam jangka waktu tertentu akan berisiko menimbulkan perasaan kelelahan kerja.

Sikap tubuh dalam bekerja merupakan gambaran bagaimana posisi badan, kepala dan anggota tubuh (tangan dan kaki) baik dalam hubungan antara bagian-bagian tubuh tersebut maupun dengan pusat gravitasinya. Beberapa faktor yang dapat mempengaruhi yaitu sudut persendiran, inklinasi vertical badan, kepala, tangan dan kaki serta derajat penambahan atau pengurangan bentuk kurva tulang belakang. Pekerjaan dalam durasi waktu yang lama dengan posisi tetap akan menyebabkan rasa tidak nyaman dan membuat pekerja harus selalu berusaha menyeimbangkan posisi tubuhnya. Sehingga dapat menyebabkan terjadinya beban kerja statis pada otot-otot punggung dan kaki. ${ }^{3}$

Kelelahan kerja (fatigue) merupakan kondisi dimana melemahnya kondisi tubuh pada saat melakukan suatu kegiatan atau pekerjaan. ${ }^{4}$ kelelahan akibat kerja dapat diartikan sebagai 


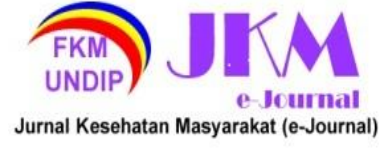

proses penurunan tingkat efisiensi, performa kerja, dan melemahnya ketahanan fisik seseorang pada saat melakukan kegiatan. Kelalahan kerja juga dapat menyebabkan terjadinya kecelakaan kerja. Apabila seorang pekerja bekerja dengan kondisi yang tidak ergonomis maka akan menimbulkan rasa tidak nyaman dan meningkatnya perasaan lelah sehingga dapat mengakibatkan penurunan produktifitas. Sikap kerja berdiri dapat lebih melelahkan daripada sikap kerja duduk dan energi yang dikeluargkan pada sikap kerja beridiri $10-15 \%$ lebih besar daripada sikap kerja duduk. ${ }^{5}$ Dalam bekerja seorang Sales Promotion Girl (SPG) harus dalam posisi berdiri dalam jangka waktu 7-8 jam per harinya dengan menggunakan sepatu high heels yang tingginya berkisar antara $3 \mathrm{~cm}$ sampai $10 \mathrm{~cm}$.

Menurut International Labour Organization (ILO) sebanyak 2,78 juta pekerja meninggal setiap tahun akibat kecelakaan kerja dan penyakit akibat kerja. Salah satu penyebab terjadinya kecelakaan akibat kerja maupun penyakit akibat kerja adalah Kelelahan Kerja. ${ }^{6}$

Pada penelitian yang dilakukan oleh Eta Berina Kuswardani, Arifin, dan Gunung Setiadi tentang "Penggunaan high heels dan kelelahan kerja pada karyawati mal di Banjarbaru tahun 2018" disebutkan bahwa dari 36 karyawati yang diambil sebagai sampel. Sebanyak 9 orang tidak mengalami kelalahan, 15 orang karyawati mengalami kelelahan kerja ringan, dan sebanyak 12 orang karyawati mengalami kelelahan sedang. ${ }^{7}$

Penelitian yang dilakukan oleh Annisa Nur Karimah tentang "Risko Penggunaan High Heels pada Kelelahan Pekerja Wanita di Pusat Perbelanjaan Kota Surakarta" tahun 2021 menyebutkan bahwa pekerja yang menggunakan high heels selama bertahuntahun megalami perubahan postur tulang jari dan kelima jadi menjadi berdempet akibat bentuk high heels. Selain itu juga mengalami Trombosis Vena Profunda (TVP) dan bahkan efeknya sampai punggung dan kepala. Akibatnya pekerja merasa kelelahan akibat pusing dan sakit punggung atau pegal. ${ }^{8}$

Penggunaan high heels tidak hanya berpengaruh pada kelelahan kerja, akan tetapi juga kejadian nyeri otot seperti pada penelitian yang dilakukan oleh Safun Rahmanto, Anita Faradilla Rahim, dan Fini Aprillia tahun 2021 bahwa pada penelitiannya menyimpulkan bahwa terdapat hubungan masa pemakaian high heels terhadap nyeri oto gastrocnemius pada karyawan sales promotion girl di kota Malang. ${ }^{9}$

Penelitian Halimatusyadian dan Deta Dwi Murlianti tentang "Hubungan Penggunaan High Heels dengan Keluhan Low Back Pain pada Sales Promotion Gril di Grand Yogya Kepatihan Bandung" juga menyebutkan bahwa menggunakan high heels memiliki tingkat risiko 6 kali lebih besar terjadinya low back pain dibandingkan menggunakan sepatu biasa (flat shoes). ${ }^{10}$

\section{METODE PENELITIAN}

Jenis penelitian ini merupakan penelitian Kuantitatif dengan pendekatan studi cross sectional. Populasi dalam penelitian ini adalah seluruh Sales Promotion Girl (SPG) yang berjumlah 150 orang di Swalayan Kota Semarang. Sampel yang akan diteliti di tentukan menggunakan rumus Lemesshow sehingga didapatkan sebanyak 38 orang. untuk mendapatkan sampel, teknik yang digunakan adalah teknik incidental sampling.

Instrumen yang digunakan dalam penelitian ini adalah lembar kuisioner IFRC (Industrial Fatigue Research Commite) untuk mengukur tingkat kelelahan yang terjadi. Microtoise, Timbangan badan digital untuk mengetahui Indeks Massa Tubuh. Penggaris untuk mengukur tinggi heels pada sepatu yang digunakan. Dan Lembar REBA (Rapid Entire Body Assessment) untuk menghitung tingkat risiko sikap kerja pada setiap responden.

\section{HASIL DAN PEMBAHASAN}

1. Analisis Univariat

a. Usia

Tabel 1. Distribusi Usia

\begin{tabular}{lll} 
Usia & $\mathbf{F}$ & Presentase $(\%)$ \\
\hline$\geq \mathbf{3 0}$ tahun & 9 & 23,7 \\
\hline$<\mathbf{3 0}$ tahun & 29 & 76,3 \\
\hline Total & 38 & 100,0
\end{tabular}

Pasa penelitian ini diketahui bahwa sebanyak 29 responden $(76,3 \%)$ berusia kurang dari 30 tahun.

b. Masa Kerja

Tabel 2. Distribusi Masa Kerja

\begin{tabular}{llll}
\hline \multicolumn{2}{l}{ Masa Kerja } & F & $\begin{array}{l}\text { Presentase } \\
(\%)\end{array}$ \\
\hline $\begin{array}{l}\text { Masa } \\
\text { Lama }\end{array}$ & Kerja & 24 & 63,2 \\
\hline $\begin{array}{l}\text { Masa } \\
\text { Baru }\end{array}$ & Kerja & 14 & 36,8 \\
\hline
\end{tabular}




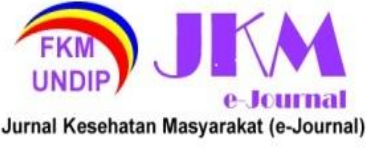

Total $38 \quad 100,0$

Pada penelitian ini diketahui bahwa sebanyak 24 responden $(63,2 \%)$ memiliki masa kerja lama yaitu lebih dari 3 tahun.

c. Status Gizi

Tabel 3. Distribusi Status Gizi

\begin{tabular}{lll}
\hline $\begin{array}{l}\text { Indeks Masa } \\
\text { Tubuh }\end{array}$ & F & Presentase (\%) \\
\hline Overweight & 12 & 31,6 \\
\hline Normal & 15 & 39,5 \\
\hline Kurus & 11 & 28,9 \\
\hline Total & 38 & 100,0
\end{tabular}

Pada penelitian ini diketahui bahwa sebanyak 15 responden (63,2\%) memilki Indeks Masa Tubuh Normal.

d. Tinggi High Heels

Tabel 4. Distribusi Tinggi Sepatu High Heels

\begin{tabular}{lll}
\hline Tinggi Hak & F & $\begin{array}{l}\text { Prese } \\
(\%)\end{array}$ \\
\hline Berisiko & 21 & 55,3 \\
\hline Tidak & 17 & 44,7 \\
Berisiko & 38 & 100,0 \\
\hline Total & 3
\end{tabular}

Pada Penelitian ini diketahui bahwa sebanyak 21 responden (55,3\%) menggunakan sepatu High Heels yang Berisiko.

e. Sikap Kerja Berdiri

Tabel 5. Distribusi Sikap Kerja Berdiri

\begin{tabular}{|c|c|c|c|}
\hline $\begin{array}{l}\text { Sikap } \\
\text { Berdiri }\end{array}$ & Kerja & & $\begin{array}{l}\text { Presentas } \\
\text { e (\%) }\end{array}$ \\
\hline Rendah & & 16 & 42,1 \\
\hline \multicolumn{2}{|c|}{ Sangat Rendah } & 22 & 57,9 \\
\hline Total & & 38 & 100,0 \\
\hline
\end{tabular}

Pada penelitian ini diketahui bahwa sebanyak 22 responden (57,9\%) memiliki sikap kerja berdiri dengan risiko sangat rendah.

f. Kelelahan Kerja

Tabel 6. Distribusi Kelelahan Kerja

\begin{tabular}{llll}
$\begin{array}{l}\text { Kelelahan } \\
\text { Kerja }\end{array}$ & F & $\begin{array}{l}\text { Presentase } \\
(\%)\end{array}$ \\
\hline Sedang & 18 & 47,4 & \\
\hline Rendah & 20 & 52,6 & \\
\hline Total & 38 & 100,0 & \\
\hline Pada penelitian ini diketahui bahwa
\end{tabular}

sebanyak 20 responden (52,6\%) mengalami kelelahan kerja tingkat rendah.

2. Analisis Bivariat

a. Hubungan Sikap Kerja Berdiri terhadap Tingkat Kelelahan Kerja

Tabel 7. Tabulasi Silang antara Sikap Kerja Berdiri dengan Tingkat Kelelahan Kerja

\begin{tabular}{cllll}
$\begin{array}{l}\text { Sikap } \\
\text { Kerja } \\
\text { Berdiri }\end{array}$ & \multicolumn{2}{l}{ Kelelahan Kerja } & Total & $\begin{array}{l}\text { P } \\
\text { value }\end{array}$ \\
\cline { 2 - 3 } & Sedang & Rendah & & \\
\hline Rendah & 11 & 5 & 16 & \\
\hline $\begin{array}{c}\text { Sangat } \\
\text { Rendah }\end{array}$ & 7 & 15 & 22 & 0,024 \\
\hline Total & 18 & 20 & 38 & \\
\hline
\end{tabular}

Hasil uji hubungan menggunakan uji Chi Square diperoleh $p$-value sebesar $0,024(p$ value $<0,05$ ) yang berarti secara statistik dapat disimpulkan bahwa terdapat hubungan yang signifikan antara sikap kerja berdiri terhadap tingkat kelelahan kerja. sikap kerja berdiri dapat meningkatkan mobilitas dan mengurangi risiko cedera pada pekerja, namun sikap kerja yang dilakukan dengan durasi yang lama tanpa istirahat atau peregangan dapat menyebabkan sakit pada kaki, terhambatnya sirkulasi peredaran darah, pembengkakan pada kaki dan tungkai bawah, serta dapat menyebabkan kelelahan pada otot kaki. ${ }^{11}$ Untuk itu diperlukan peregangan sebelum memulai pekerjaan untuk mempersiapkan otot, dan saat tubuh mulai merasakan lelah. Pada Sales Promotion Girl (SPG) kelelahan yang diakibatkan karena sikap kerja berdiri terletak pada tumpuan kaki yang tidak ergonomis, kondisi penggunaan high heels mengakibatkan tumit yang lebih tinggi daripada jari-jari kaki sehingga menyebabkan terjadinya kelelahan.

Hasil penelitian ini sejalan dengan penelitian yang di lakukan oleh Isnaini Misbakhul Khasanah (2016) yang menunjukan bahwa dari 47 responden yang diteliti sebanyak 16 orang (34\%) mengalami kelelahan tingkat rendah dan 22 orang $(46,8 \%)$ mengalami kelelahan kategori sangat tinggi. Instrumen yang digunakan pada penelitian ini adalah formulir pengukuran metode Owas dan Kuisioner kelelahan subjektif. ${ }^{12}$

b. Hubungan Karakteristik Pekerja terhadap Tingkat Kelelahan Kerja

1. Usia

Tabel 8. Tabulasi Silang antara Usia dengan Tingkat Kelelahan Kerja

\begin{tabular}{lllll}
\multirow{2}{*}{ Usia } & \multicolumn{2}{c}{ Kelelahan Kerja } & Total & $\begin{array}{l}\text { P } \\
\text { value }\end{array}$ \\
\cline { 2 - 3 } & Sedang & Rendah & & \\
\hline $\begin{array}{lllll}\geq 30 \\
\text { tahun }\end{array}$ & 3 & 6 & 9 & \multirow{2}{*}{0,334} \\
\hline$<30$ & 15 & 14 & 29 & \\
\hline
\end{tabular}




\section{tahun}

\section{Total} 18

20

38

Hasil uji hubungan menggunakan uji Chi Square diperoleh $p$-value sebesar $0,334(p$ value $>0,05$ ) yang berarti secara statistik dapat disimpulkan bahwa tidak ada hubungan yang signifikan antara usia dengan kelelahan kerja. Usia merupakan umur yang terhitung dari saat kelahiran hingga akan berulang tahun, jika seseorang memiliki umur yang cukup, tingkat kekuatan dan kematangan dalam berfikir dianggap sudah mumpuni dalam mendapat tanggung jawab pada pekerjaannya. Usia bukan merupakan faktor utama terjadinya kelelahan kerja melainkan sebagai faktor kombinasi. Usia tidak berdiri sendiri sebagai penyebab kelelahan kerja tetapi ada faktor penyebab lain yang lebih dominan.

Hasil penelitian ini sejalan dengan penelitian yang dilakukan oleh Rayi Trinofiandy (2018). instrumen yang digunakan sama dengan yang digunakan peneliti yaitu lembar Kuisioner IFRC menunjukan bahwa tidak ada hubungan yang signifikan antara usia dengan tingkat kelelahan kerja karena pada penelitian ini responden lebih banyak dalam kategori usia remaja akhir dan dewasa 21-35 tahun sehingga masih masuk dalam usia produktif. instrumen yang digunakan sama dengan yang digunakan peneliti yaitu lembar Kuisioner IFRC. ${ }^{13}$

2. Masa Kerja

Tabel 9. Tabulasi Silang antara Masa Kerja dengan Tingkat Kelelahan Kerja

\begin{tabular}{cllll} 
Masa & \multicolumn{2}{l}{ Kelelahan Kerja } & Total & P value \\
\cline { 2 - 5 } Kerja & Sedang & Rendah & \\
& 13 & 11 & 24 & 0,272 \\
\hline Lama & 5 & 9 & 14 & \\
\hline Baru & 5 & 20 & 38 & \\
\hline Total & 18 & 20 &
\end{tabular}

Hasil uji hubungan menggunakan uji $C h i$ Square diperoleh $p$-value sebesar $0,272(p$ value $>0,05$ ) yang berarti secara statistik dapat disimpulkan bahwa tidak ada hubungan yang signifikan antara masa kerja dengan kelelahan kerja. Masa kerja merupakan akumulasi aktivitas kerja seseoranng yang dilakukan dalam jangka waktu yang Panjang.

Hasil penelitian ini sejalan dengan penelitian yang dilakukan oleh Rayi Trinofiandy (2018) tidak ada hubungan yang signifikan antara masa kerja dengan tingkat kelelahan kerja. ${ }^{13} \mathrm{Hal}$ ini dikarenakan orang yang memiliki masa kerja lama akan merasa terbiasa dengan beban pekerjaan yang dilakukannya sehingga tidak menimbulkan kelelahan kerja lagi bagi dirinya. ${ }^{14}$ Selain tiu juga massa kerja yang lama menjadikan pekerja memiliki pengalaman yang banyak. Artinya karyawan yang memiliki pengalaman yang banyak akan menghasilkan produktivitas kerja yang tinggi. ${ }^{15}$

3. Status Gizi (Indeks Massa Tubuh) Tabel 10. Tabulasi Silang antara IMT dengan Tingkat Kelelahan Kerja

\section{Status Gizi Kelelahan Kerja Total $\begin{aligned} & \mathbf{P} \\ & \text { (IMT) }\end{aligned}$ value Sedang Rendah}

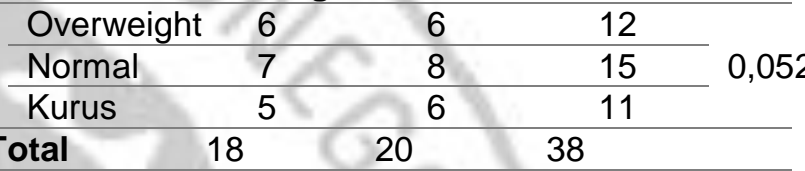

Hasil uji hubungan menggunakan uji Chi Square diperoleh $p$-value sebesar 0,052 ( $p$ value $>0,05$ ) yang berarti secara statistik dapat disimpulkan bahwa tidak ada hubungan yang signifikan antara Indeks Massa Tubuh (IMT) dengan kelelahan kerja. Dengan indeks massa tubuh maka dapat diketahui apakah seseorang masuk dalam kategori kurus, normal, overweight, maupun obesitas. Pada penelitian ini mayoritas respondedn memiliki indeks massa tubuh yang normal sehingga tidak mempengaruhi pada kegiatan pekerjaan yang dilakukan.

Hasil penelitian ini tidak sejalan dengan penelitian yang dilakukan oleh Fenita Purnama Sari Indah (2021) yang menyatakan bahwa ada hubungan yang signifikan antara Indeks Massa Tubuh (IMT) dengan tingkat kelelahan kerja. hal ini disebabkan karena pada penelitian tersebut sebanyak $86,1 \%$ responden memiliki Indeks massa tubuh tidak normal. Indeks massa tubuh yang tidak normal akan mempengaruhi aktivitas kerja seseorang. ${ }^{16}$

c. Hubungan Penggunaan High Heels terhadap Tingkat Kelelahan Kerja Tabel 11. Tabulasi Silang antara Penggunaan High Heels dengan Tingkat Kelelahan Kerja

\begin{tabular}{lllll}
$\begin{array}{l}\text { Tinggi } \\
\text { High } \\
\text { Heels }\end{array}$ & \multicolumn{2}{l}{ Kelelahan Kerja } & Total & $\begin{array}{l}\mathbf{P} \\
\text { value }\end{array}$ \\
\cline { 2 - 5 } & Sedang & Rendah & & \\
\hline Berisiko & 14 & 7 & 21 & 0,008 \\
\hline Tidak & 4 & 13 & 17 & \\
\hline
\end{tabular}




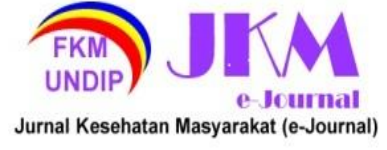

JURNAL KESEHATAN MASYARAKAT (e-Journal)

Volume 9, Nomor 6, November 2021

ISSN: 2715-5617 / e-ISSN: 2356-3346

http://ejournal3.undip.ac.id/index.php/jkm

\section{Berisiko}

$\begin{array}{llll}\text { Total } & 18 & 20 & 38\end{array}$

Hasil uji hubungan menggunakan uji Chi Square diperoleh $p$-value sebesar 0,008 ( $p$ value $<0,05$ ) yang berarti secara statistik dapat disimpulkan bahwa ada hubungan yang signifikan antara penggunaan high heels dengan kelelahan kerja. Penggunaan high heels merupakan salah satu faktor yang menyebabkan terjadinya kelelahan kerja hal ini dapat disebabkan karena kondisi dimana tumit kaki lebih tinggi daripada jari-jari kaki pada pengguna sepatu high heels sehingga dapat menyebabkan timbulnya gangguan kesehatan maupun gangguan pada tulang seperti lordosis. ${ }^{17}$

Kelelahan yang di akibatkan oleh penggunaan high heels dapat juga di kategorikan pada kelelahan otot. Seperti pada penelitian yang dilakukan oleh Indah Amin Sugiharti (2017) menyatakan bahwa penggunaan high heels berpengaruh pada intensitas nyeri daerah calcaneus posterior dan calcaneus medial. 18

Akan tetapi hasil penelitian ini tidak sejalan dengan penelitian yang dilakukan oleh Eta Berina Kuswardani (2017) yang menyatakan bahwa tidak ada hubungan yang signifikan antara tinggi hak sepatu dengan tingkat kelelahan kerja. Dari 36 responden yang di teliti sebanyak 21 orang menggunakan sepatu high heels dengan tinggi sedang $(3-5 \mathrm{~cm})$ yang artinya tidak berisiko untuk mengalami kelelahan kerja. $^{7}$

\section{KESIMPULAN}

Berdasarkan hasil analisis data dan pembahasan yang dilakukan, maka dapat diperoleh kesimpulan sebagai berikut :

1. Responden yang berusia $<30$ tahun sebanyak 29 orang $(76,3 \%)$

2. Responden yang memiliki masa kerja lama ( $\geq 3$ tahun) sebanyak 24 orang $(63,2 \%)$

3. Sebagian besar responden memiliki Indeks Massa Tubuh Normal sebanyak 12 orang $(39,5 \%)$

4. Responden yang menggunakan sepatu High Heels dengan hak berisiko $(\geq 5 \mathrm{~cm})$ sebanyak 21 orang $(55,3 \%)$

5. Responden yang dengan sikap kerja berdiri yang berisiko sangat rendah sebanyak 16 orang $(57,9 \%)$

6. Terdapat hubungan antara sikap kerja berdiri $(p$-value $=0,024)$, penggunaan high heels $(p$ - value $=0,008)$ terhadap tingkat kelelahan kerja pada Sales Promotion Girl (SPG) Swalayan di Semarang.

7. Tidak ada hubungan antara karakteristik pekerja ; Usia ( $p$-value $=0,334)$, Masa Kerja $(p$-value $=0,272)$, Indeks Massa Tubuh ( $p$ value $=0,052)$ terhadap tingkat kelelahan kerja pada Sales Promotion Girl (SPG) Swalayan di Semarang.

\section{SARAN}

1. Bagi Perusahaan

Memberikan kebijakan baru pada Sales Promotion Girl (SPG) maupun karyawati untuk menggunakan sepatu high heels yang tinggi heels nya maksimal adalah $5 \mathrm{~cm}$ dan diperbolehkan beristirahat sesaat sehingga mengurangi kejadian kelelahan kerja.

2. Bagi Pekerja Disarankan menggunakan sepatu high heels dengan tinggi heels kurang dari $5 \mathrm{~cm}$ dan melakukan peregangan sebelum bekerja.

3. Bagi Peneliti lain

Meneliti faktor lain diluar pekerjaan seperti riwayat penyakit, aktivitas dirumah, dan faktor lainya yang dapat mempengaruhi kelelahan kerja dan menggunakan instrumen yang berbeda untuk mengukur kelelahan kerja.

\section{DAFTAR PUSTAKA :}

1. Bültmann U, Kant I, Kasl S V., Beurskens AJHM, Van Den Brandt PA. Fatigue and psychological distress in the working population psychometrics, prevalence, and correlates. J Psychosom Res. 2002;52(6):445-52.

2. Septian Y, Merijanti LT. Pemakaian sepatu hak tinggi berhubungan dengan nyeri otot betis pada pramuniaga. J Biomedika dan Kesehat. 2018;1(2):158-63.

3. Diploma P, Keselamatan I V, Kesehatan Dan, Kedokteran F, Sebelas U. Muskuloskeletal Pada Pekerja Bagian Weaving Di Pt. Delta Merlin Dunia Tekstil Kebakkramat. 2012.

4. M. Sugeng Budiono A. Bunga Rampai Hiperkes dan Keselamatan Kerja. Semarang: Badan Penerbit UNDIP; 2003.

5. Grandjean E. Fitting the task to the Man. London: Taylor \& Francis; 1993.

6. ILO. International Occupational Safety and Health Information Centre. ILO Cat Publ Data [Internet]. 2009;p9-21. Available from: 


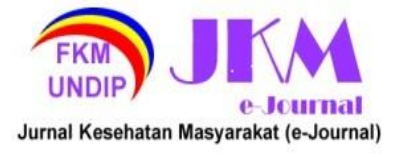

http://www.ilo.org/public/english/protection/sa fework/cis/products/bulletin.htm

7. Eta Berina Kuswardani, Arifin GS. Penggunaan High Heels Dan Kelelahan Kerja Pada Karyawati Mal. 2018;2(1):22749.

8. karimah A. Risiko Penggunaan High Heels pada Kelelahan Pekerja Wanita di Pusat Perbelanjaan Kota Surakarta. 2020.

9. Rosintan, Napitupulu M. Jurnal fisioterapi dan rehabilitasi. Fisioter Dan Rehabil. 2021;5(1):76-95.

10.Murlianti DD, Halimatusyadiah. Hubungan Penggunaan High Heels dengan Keluhan Low Back Pain pada Sales Promotion Girl di Grand Yogya Kepatihan Bandung. J Kesehat Aeromedika. 2018;4(1):17-24.

11.Welding S, Pt DI. Hubungan Antara Postur Kerja Berdiri Dengan Keluhan Nyeri Kaki Pada Pekerja Aktivitas Mekanik Section Welding Di Pt. X. J Kesehat Masy. 2017;5(5):369-77.

12.Khasanah IM. Hubungan Risiko Kerja Berdiri dengan Tingkat Kelelahan Kerja Pada Operatot Mesin Tenun PT. Iskandar Indah Printing Textile SUrakarta. Fak IImu Kesehat Univ Muhammadiyah Surakarta. 2016;1-13.

13. Trinofiandy $R$, Krisdawati $A$, Wulandari $P$. Analisis Hubungan Karakteristik Individu, Shift Kerja , dan Masa Kerja dengan Kelelahan Kerja Pada Perawat di Rumah Sakit X Jakarta Timur. J Kesehat Masy [Internet]. 2018;2(10):204-9. Available from: http://ejournal.urindo.ac.id/index.php/jukmas 204

14.Verawati L. Hubungan Tingkat Kelelahan Subjektif Dengan Produktivitas Pada Tenaga Kerja Bagian Pengemasan Di Cv Sumber Barokah. Indones J Occup Saf Heal. 2017;5(1):51.

15.IImiah J, Pandapotan ET. Karyawan ( Studi Kasus Pada Pt. Gandum. 2013;

16. Waldani D. Hubungan Indeks Massa Tubuh (IMT) dengan Kelelahan Pada Pengemudi di Bus CV. PO Safa Marwa Sungai Penuh Tahun 2019. Ensiklopedia J. 2020; Volume 2(3):231-8.

17. Yunus FI y, Sumekar A, Anisah N. Hubungan Sikap Kerja Berdiri Dan Beban Kerja Fisik Dengan Kelelahan Kerja Pada Pekerja Di Bagian Produksi Pabrik Kayu Lapis Yogyakarta. J Formil (Forum IImiah) Kesmas Respati. 2019;4(2):151.

18.Pratama ferina nadya. Digital Digital
Repository Repository Universitas Universitas Jember Jember Staphylococcus aureus Digital Digital Repository Repository Universitas Universitas Jember Jember. Skripsi. 2020.
Volume 9, Nomor 6, November 2021

ISSN: 2715-5617 / e-ISSN: 2356-3346

http://ejournal3.undip.ac.id/index.php/jkm 